\title{
Provincial squeeze on generic prices continues
}

$\mathrm{T}$ he clampdown on generic drug payments is becoming a nationwide vise as Nova Scotia has joined the bevy of provinces who'll reduce prices paid for knockoffs.

Under Nova Scotia's new "Fair Drug Pricing Act," the province's pharmacare program will pay just $45 \%$ of the cost of a brand drug for an equivalent generic. Over the next year, the cap will drop to $35 \%$.

"Nova Scotia is just following a trend started by Ontario last year," says Marc-André Gagnon, an assistant professor with the School of Public Policy and Administration at Carleton University in Ottawa, Ontario.

Ontario launched the trend toward reducing provincial drug payments by reducing payments for generics to $25 \%$ of the list price of the original brand product in the province's drug benefit program.

The benefits of Ontario's July 2010 decision will eventually flow through to consumers, says Andrew Morrison, spokesperson for the Ministry of Health and Long-Term Care in Toronto. There will be "a gradual decrease in generic drug pricing in the private market over the next three years for private employer drug plans and people who pay for drugs out of pocket."

Quebec, British Columbia and Saskatchewan have since followed suit, while Alberta is currently reviewing a similar strategy.

Two key factors are fueling the measures, says Ingrid Sketris, professor of pharmacology at Dalhousie University in Halifax, Nova Scotia. "People are concerned with high drug costs and having a sustainable system."

Others say that with many brandname drugs coming off patent in the next few years, the provinces are looking to curb costs by reducing the amount they'll pay for generics. "There was a profusion of drugs through the ' 80 s and ' 90 s. Those that were new are coming off patent. Governments are hoping for a substantial windfall," notes Dr. David Henry, profes-

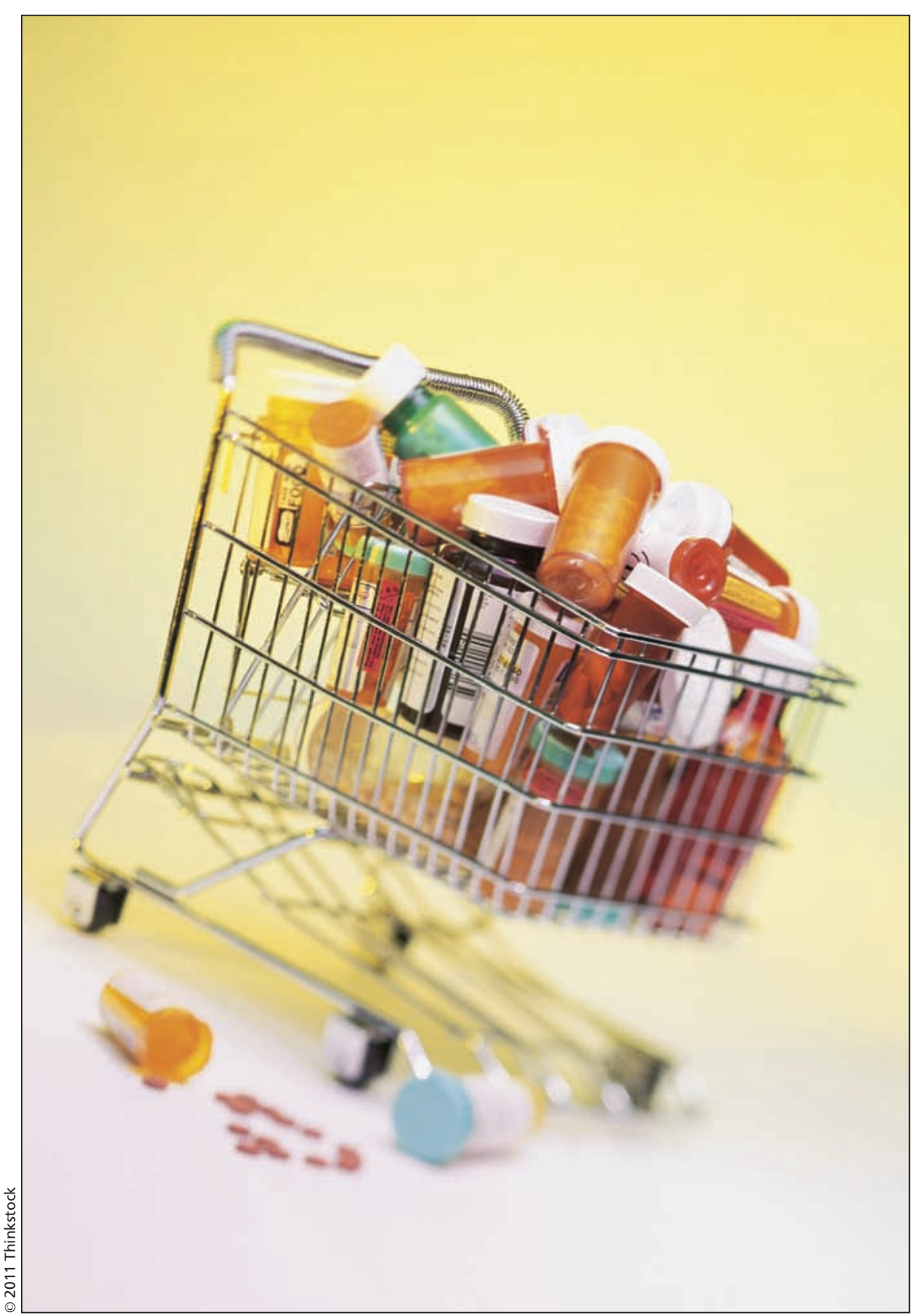

The provinces hope to shave millions from their pharmaceutical shopping bill by reducing payments for generics.

sor of medicine at the University of Toronto in Ontario and CEO of the Institute for Clinical Evaluative Sciences.

The provinces are also peeved that they're paying higher prices for generics than governments in non-Canadian jurisdictions. "Governments have come to realize they are paying way higher rates than the US [United States]," notes Dr. Jim Wright, professor of medicine at the University of British Columbia in Vancouver.

Before introducing its legislation, Nova Scotia, for example, was paying 
$63 \%$ of a generic's price compared with its brand-name equivalent.

While that figure will ultimately drop to $35 \%$, it's still excessive, says Wright. "In my opinion, 35\% of the brand name price is still way too high. It should be more like $5 \%$. In the US, where there is more competition, they are this low."

But there are risks to reducing generic prices, says Sketris. "There is a concern about the financial viability of some pharmacies especially independent pharmacies. Independent pharmacies on average derive a higher percentage of their revenues due to prescription drugs as compared to items in the front store."

Ensuring future access may be another problem, says Henry. "In the US, they are getting multiple drug shortages. It seems that the very low prices of generics in some cases are making them unattractive to manufacturers."

Forcing manufacturers to lower costs in one province may also result in them increasing costs in provinces where no cap exists, says Gagnon. "In general, fixing [prices] for generics is not the best policy."

"We need more bulk purchasing for provinces and a tender process for the lowest [bid]," he adds. "We could achieve more savings and benefit the most from market competition." donalee Moulton, Halifax, NS

CMAJ 2011. DOI:10.1503/cmaj.109-3966 